\title{
Pure-Tone Hearing Thresholds and Brainstem Auditory Evoked Potentials in Sporadic Ataxia
}

\author{
Bianca Simone Zeigelboim ${ }^{1}$ Anylize Wachholz Vom Scheidt ${ }^{2} \quad$ Kairone Fernandes Kronbauer ${ }^{2}$ \\ Paulo Breno Noronha Liberalesso ${ }^{3}$ Maria Renata José ${ }^{4}$ Vinicius Ribas Fonseca ${ }^{5}$ \\ Hélio Afonso Ghizoni Teive ${ }^{5}$
}

1 Department of Otoneurology, Universidade Tuiuti do Paraná,

Curitiba, PR, Brazil

2 Postgraduation Program in Communication Disorders, Universidade

Tuiuti do Paraná, Curitiba, PR, Brazil

${ }^{3}$ Department of Pediatric Neurology, Hospital Pequeno Príncipe,

Curitiba, PR, Brazil

${ }^{4}$ Department of Otorhinolaryngology, Universidade Tuiuti do Paraná, Curitiba, PR, Brazil

${ }^{5}$ Department of Neurology, Universidade Federal do Paraná,

Curitiba, PR, Brazil

\begin{abstract}
Address for correspondence Bianca Simone Zeigelboim, PhD, Postgraduation Program in Communication Disorders, Universidade Tuiuti do Paraná, Rua Sydnei Antônio Rangel, 245 - Santo Inácio, Curitiba, PR, 82010-330, Brazil (e-mail: biancacwb@yahoo.com.br).
\end{abstract}

Int Arch Otorhinolaryngol 2020;24:e86-e92.

\begin{abstract}
Keywords

- spinocerebellar degenerations

- hearing

- hearing disorders

- audiometry

- evoked response audiometry

Introduction Spinocerebellar ataxia (SCA) is part of a genetic and clinical heterogeneous group of neurodegenerative diseases characterized by progressive cerebellar ataxia.

Objective To describe the results of audiological and electrophysiological hearing evaluations in patients with sporadic ataxia (SA).

Methods A retrospective cross-sectional study was carried out with 11 patients submitted to the following procedures: anamnesis, otorhinolaryngological evaluation, tonal and vocal audiometry, acoustic immittance and brainstem auditory evoked potential (BAEP) tests.

Results The patients presented with a prevalence of gait imbalance, of dysarthria, and of dysphagia; in the audiometric and BAEPs, four patients presented with alterations; in the acoustic immittance test, five patients presented with alterations, predominantly bilateral.

Conclusion The most evident alterations in the audiological evaluation were the prevalence of the descending audiometric configuration between the frequencies of 2 and $4 \mathrm{kHz}$ and the absence of the acoustic reflex between the frequencies of 3 and $4 \mathrm{kHz}$ bilaterally. In the electrophysiological evaluation, the patients presented changes with a prevalence of increased I, III and $\mathrm{V}$ wave latencies and the interval in the interpeak I-III, I-V and III-V. In the present study, it was observed that auditory complaints did not have a significant prevalence in this type of ataxia, which does not occur in some types of autosomal recessive and dominant ataxia.
\end{abstract}

received

January 3, 2019

accepted

June 6, 2019
DOI https://doi.org/

10.1055/s-0039-1693676.

ISSN $1809-9777$.
Copyright $\odot 2020$ by Thieme Revinter

Publicações Ltda, Rio de Janeiro, Brazil
License terms

c) $(\oplus) \$$ 


\section{Introduction}

Ataxias are a group of neurodegenerative diseases featuring the presence of progressive cerebellar disorder, followed by several neurological signs and symptoms, such as balance and motor coordination disorders, besides the presence of eye dysfunctions. ${ }^{1,2}$

Ataxias can be divided in six large groups: a) autosomal recessive hereditary ataxias; b) autosomal dominant hereditary ataxias; c) congenital ataxias; d) X-associated ataxia syndrome; e) mitochondrial ataxias; and f) sporadic ataxias (SAs). ${ }^{3-5}$ The last type is the group of interest in the present study.

Sporadic ataxia is classified as a rare neurological condition, of late onset, usually in individuals $>40$ years old, with no family history, and with a wide range of potential causes. Among them, cerebellar degeneration, alcohol abuse, paraneoplastic syndrome, heavy metal poisoning (toxic reaction), dysfunction of the neuroimmune system, E, B1, B12 vitamin deficiency, infectious diseases (neurosyphilis, Whipple disease, Lyme disease, and human immunodeficiency virus [HIV]), and degenerative diseases can be pointed out. ${ }^{4,5}$

Drumond et $\mathrm{al}^{6}$ pointed out the complexity of the differential diagnosis of SA, as well as the difficulty in determining its etiology due to its heterogeneity. When its onset occurs after the age of 50 years old, a wide investigation cannot be enough to detect its etiology; therefore, it can be classified as lateonset idiopathic cerebellar ataxia.

Sporadic adult-onset ataxia (SAOA) of unknown etiology is a nonhereditary disorder, distinct from multiple system atrophy. Despite its unknown cause, it is considered as a set of disorders comprising a common clinical syndrome. Epidemiological studies have found prevalence rates ranging from 2.2 to 8.4 per 100,000 individuals. About a third of the SAOA patients have polyneuropathy or affection of the pyramidal tract observed with cerebellar ataxia, although cognitive impairment is not common or present in a mild degree. Neuropathological and imaging studies have shown isolated cerebellar cortical degeneration and mild brainstem atrophy, although there is no established therapeutics for SAOA. ${ }^{4}$

The neurobiological hearing components involve a complexity of events, as well as broad interrelationships in the central nervous system (CNS). ${ }^{7}$

Assessment of the peripheral and central hearing systems is performed by means of behavioral, electroacoustic, and electrophysiological tests. Peripheral hearing involves the amplification and conduction of sound waves, as well as the perception of sound vibrations that are changed into nervous impulses. Central hearing involves the conduction of nervous impulses by means of the ear pathway to the hearing cortex, where they will be coded and recoded, thus gaining linguistic meaning. Brainstem auditory responses will be assessed by means of the electrical activities in the auditory nerve. The effects caused by degenerative processes may involve the central auditory nervous system (CANS). ${ }^{8}$

In some types of cerebellar ataxia, Ikeda et al, Mahmoud, and Zeigelboim et $\mathrm{al}^{9-11}$ had a large percentage of subjects with hearing loss verified through the audiological evaluation.
Some studies, ${ }^{11-13}$ using electrophysiological tests in patients with cerebellar ataxia, already verified abnormalities in brainstem auditory evoked potentials (BAEPs) in $>50 \%$ of the evaluated subjects, while other studies ${ }^{14,15}$ evidenced abnormality in 71 and $46.5 \%$, respectively, in the BAEP assessment of autosomal recessive and dominant spinocerebellar ataxias. In the acoustic immittance measurement, Zeigelboim et $\mathrm{al}^{11}$ reported disorders in $46.6 \%$ of the sample of patients with neurodegenerative diseases, and $44.1 \%$ of abnormality in patients with autosomal dominant spinocerebellar ataxia, ${ }^{15}$ mainly related to acoustic reflexes.

Due to the audiological findings found in the literature on the alterations observed in ataxia patients, the present study aimed to describe the results of audiological and electrophysiological screening in patients with $\mathrm{SA}$, which is classified as a rare neurological condition.

\section{Methods}

The research protocol was approved by the Ethics Committee on Research Involving Human Subjects (registration number: 832.502/2014) at Platform Brazil. All of the examinations were performed after informed consent forms were obtained from all of the participants.

A retrospective cross-sectional study was carried out, assessing 11 patients ( 4 females and 7 males) diagnosed with SA referred by the Department of Internal Medicine of the Clinical Hospital for assessment in the Department of Otoneurology of a teaching institution in the same city, diagnosed with SCA, sporadic form. Their diagnosis was performed by means of their clinical history, neurological and imaging screening, and genetic testing using polymerase chain reaction (PCR). ${ }^{16-18}$

The age of the patients ranged from 35 to 58 years old ( $46.6 \pm 8$ years old). The time span of the disease ranged from 4 to 13 years $(8.8 \pm 2.8$ years $)$, as shown in - Table 1 .

The evaluated patients did not report a history of exposure to noise nor the use of ototoxic drugs. They reported a family history of presbycusis (two cases), of hypertension (six cases), and of diabetes (three cases).

Patients with auditory disorders and difficulty in understanding simple commands, which would hinder the screening, were excluded from the research.

All of the patients underwent an analysis of their clinical history and an otorhinolaryngological screening.

Audiological evaluation - The patients were submitted to pure tone air conduction threshold audiometry, frequencies from 0.25 to $8 \mathrm{kHz}$; pure tone bone conduction threshold audiometry, frequencies from 0.5 to $4 \mathrm{kHz}$; speech recognition threshold (SRT) and speech discrimination score (SDS). For these tests, the Madsen Itera II equipment (Otometrics A/S, Taastrup, Denmark), TDH-39 heaphones (Telephonics Corp., Farmingdale, NY, USA), and thresholds in $\mathrm{dBH}$ were used. The equipment was calibrated according to ISO 8253. The level and type of hearing loss were analyzed according to Davis et al and Silman et al. ${ }^{19,20}$

Brainstem auditory evoked potential - This test used 2 channels with a click stimulus in $90 \mathrm{dBHL}$, alternate polarity with a presentation frequency of $21.1 \mathrm{c} / \mathrm{s}$, window of $15 \mathrm{~ms}$, 
Table 1 Sporadic ataxia aspects

\begin{tabular}{|l|l|l|l|l|}
\hline Case & $\begin{array}{l}\text { Age } \\
\text { (years old) }\end{array}$ & Gender & SARA & $\begin{array}{l}\text { Disease } \\
\text { duration (years) }\end{array}$ \\
\hline 1 & 58 & M & 22.5 & 12 \\
\hline 2 & 36 & F & 16 & 7 \\
\hline 3 & 43 & M & 10 & 12 \\
\hline 4 & 37 & M & 8.5 & 8 \\
\hline 5 & 46 & F & 11.5 & 10 \\
\hline 6 & 49 & M & 13 & 13 \\
\hline 7 & 54 & F & 7 & 8 \\
\hline 8 & 35 & F & 14 & 6 \\
\hline 9 & 48 & M & 12.5 & 10 \\
\hline 10 & 54 & M & 20.5 & 4 \\
\hline 11 & 53 & M & 10 & 7 \\
\hline
\end{tabular}

Abbreviations: F, female; M, male; SARA, scale for the assessment and rating of ataxia.

30 to $3 \mathrm{kHz}$ filter, and at least 2,000 stimuli, and 2 rounds of reproduction. Kendall Medi-Trace 2000 electrodes were placed on the right and left mastoids, and Fz (10-20 system) and ground electrodes were used on the forehead. Clicks were presented by $3 \mathrm{~A}$ insert earphones. Wave latencies I, III and $\mathrm{V}$, and interpeak intervals I-III, III-V, I-V were analyzed according to Hall. ${ }^{21}$ The equipment used was Bio-logic Evoked Potential NavPRO-ONE System (Otometrics A/S, Taastrup, Denmark).

Acoustic immittance evaluation - This procedure has been performed to access the integrity of the middle ear according to Jerger. ${ }^{22}$ The acoustic immittance equipment used was Madsen Otoflex 100 (Otometrics A/S, Taastrup, Denmark).

For the statistical analysis, the Fisher exact test was applied, aiming to compare the results of the audiological testing, of the BAEP and acoustic immittance measurement (analyzing normal and abnormal results), and to relate the audiological findings, BAEP and accoustic immitance measurement to the following variables: duration of the disease, age and Scale for the Assessment and Rating of Ataxia (SARA scale). The null hypothesis rejection rule was established at 0.05 or $5 \%$. The Statistica 13.1 software (Dell Software Inc., Round Rock, TX, USA) was used.

\section{Results}

The most reported complaints in the anamnesis were: gait imbalance (81.8\%), dysarthria (63.8\%). and dysphagia (54.5\%). Dizziness, dysphonia, tremor, fall, and irradiated pain to the shoulders and the arms were reported by $45.4 \%$ of the patients. Tinnitus and hearing loss were referred by 36.3\% of the patients, as shown in - Table 2.

The application of the Fisher exact test evidenced a statistically significant difference in the proportion of cases with gait imbalance when compared with tinnitus $(p=0.0402)$ and with hearing loss $(p=0.0402)$, which were the most evidenced symptoms.
Table 2 Frequency of symptoms of 11 patients with sporadic ataxia

\begin{tabular}{|l|l|l|}
\hline Symptoms & Number of patients & Frequency (\%) \\
\hline Gait imbalance & 9 & 81.8 \\
\hline Dysarthria & 7 & 63.8 \\
\hline Dysphagia & 6 & 54.5 \\
\hline Dizziness & 5 & 45.4 \\
\hline Dysphonia & 5 & 45.4 \\
\hline Tremor & 5 & 45.4 \\
\hline Fall & 5 & 45.4 \\
\hline $\begin{array}{l}\text { Pain, irradiated } \\
\text { to shoulder, arm }\end{array}$ & 5 & 45.4 \\
\hline $\begin{array}{l}\text { Extremities } \\
\text { tingling }\end{array}$ & 4 & 36.3 \\
\hline Tinnitus & 4 & 36.3 \\
\hline Hearing loss & 4 & 36.3 \\
\hline Anxiety & 3 & 27.2 \\
\hline Blurred vision & 3 & 27.2 \\
\hline Diplopia & 3 & 27.2 \\
\hline Fatigue & 3 & 27.2 \\
\hline Depression & 3 & 27.2 \\
\hline Insomnia & 2 & 18.1 \\
\hline Taste alteration & 1 & 9.0 \\
\hline
\end{tabular}

In the audiological evaluation, 4 patients (36.4\%) had altered results, with bilateral prevalence, as shown in - Table 3.

The Fisher exact test was used to compare the frequency of alterations in the auditory thresholds of subjects with SA. No statistically significant difference was found between the frequency of ears that presented alterations in the auditory thresholds and of those that presented normal auditory thresholds ( $p=0.1974)$.

The results from the SRT and SDS matched the tonal thresholds.

Regarding the BAEP assessment, 4 patients (36.4\%) evidenced altered testing: $18.2 \%$ bilaterally, and $18.2 \%$ in the left ear, according to - Table 3.

The alterations observed in BAEP were: increase of the latency of wave I (case 11), of wave III (cases 6, 9 and 11), of wave $\mathrm{V}$ (cases 1, 6, 9 and 11), and of the interpeak intervals IIII, IV, and III-V (cases 1, 6, 9 and 11).

The application of the Fisher exact test showed a statistically significant difference between the frequency of ears that presented alterations in BAEP and those that presented normal auditory results in this evaluation $(p=0.0030)$.

In the acoustic immittance measurement, 5 patients (45.4\%) evidenced abnormal testing, with bilateral prevalence, as shown in - Table 4.

The Fisher exact test was used to compare the frequency of alterations in acoustic immittance of subjects with SA. No statistically significant difference was found between the 
Table 3 Results of audiological and brainstem auditory evoked potential evaluations in 11 patients with sporadic ataxia

\begin{tabular}{|c|c|c|c|c|}
\hline \multirow[t]{2}{*}{ Patients } & \multicolumn{2}{|l|}{ Audiological evaluation } & \multicolumn{2}{|c|}{$\begin{array}{l}\text { Brainstem auditory } \\
\text { evoked potential }\end{array}$} \\
\hline & Right ear & Left ear & Right ear & Left ear \\
\hline 1 & Down-sloping hearing loss beginning at $2 \mathrm{kHz}$ & Down-sloping hearing loss beginning at $2 \mathrm{kHz}$ & Abnormal & Abnormal \\
\hline 2 & Normal & Normal & Normal & Normal \\
\hline 3 & Normal & Normal & Normal & Normal \\
\hline 4 & Normal & Normal & Normal & Normal \\
\hline 5 & Normal & Normal & Normal & Normal \\
\hline 6 & Down-sloping hearing loss beginning at $4 \mathrm{kHz}$ & SNHL moderate & Normal & Abnormal \\
\hline 7 & Down-sloping hearing loss beginning at $4 \mathrm{kHz}$ & Down-sloping hearing loss beginning at $4 \mathrm{kHz}$ & Normal & Normal \\
\hline 8 & Normal & Normal & Normal & Normal \\
\hline 9 & Normal & Normal & Abnormal & Abnormal \\
\hline 10 & Normal & Normal & Normal & Normal \\
\hline 11 & Down-sloping hearing loss beginning at $4 \mathrm{kHz}$ & SNHL severe & Normal & Abnormal \\
\hline
\end{tabular}

Abbreviation: SNHL, sensorineural hearing loss.

Table 4 Results of the acoustic immittance test in 11 patients with sporadic ataxia

\begin{tabular}{|c|c|c|c|c|}
\hline \multirow[t]{3}{*}{ Patients } & \multicolumn{4}{|c|}{ Acoustic immittance evaluation } \\
\hline & \multicolumn{2}{|l|}{ Right ear } & \multicolumn{2}{|l|}{ Left ear } \\
\hline & Tympanometric & Acoustic reflex & Tympanometric & Acoustic reflex \\
\hline 1 & Type A & Absent in the 3 and $4 \mathrm{kHz}$ frequencies & Type A & Absent in the 3 and $4 \mathrm{kHz}$ frequencies \\
\hline 2 & Type A & Present & Type A & Present \\
\hline 3 & Type A & Present & Type A & Present \\
\hline 4 & Type A & Present & Type A & Present \\
\hline 5 & Type A & Present & Type A & Present \\
\hline 6 & Type A & Absent in the $4 \mathrm{kHz}$ frequency & Type A & Absent \\
\hline 7 & Type A & Absent in the $4 \mathrm{kHz}$ frequency & Type A & Absent in the $4 \mathrm{kHz}$ frequency \\
\hline 8 & Type A & Present & Type A & Present \\
\hline 9 & Type A & Absent in the 3 and $4 \mathrm{kHz}$ frequencies & Type A & Absent in the 3 and $4 \mathrm{kHz}$ frequencies \\
\hline 10 & Type A & Present & Type A & Present \\
\hline 11 & Type A & Absent in the 3 and $4 \mathrm{kHz}$ frequencies & Type A & Absent \\
\hline
\end{tabular}

frequency of ears that presented alterations in this test and those that presented normal auditory results $(p=0.5000)$.

The relation between the audiological findings, BAEP, and acoustic immittance with variables for age, disease duration, and SARA scale can be observed in - Table $\mathbf{5}$.

The application of the Fisher exact test verified no statistically significant difference between the audiological finding, BAEP and acoustic immittance with variables for disease duration $(p=0.6515),(p=0.1970)$ and $(p=0.3918)$ age $(p=0.0879),(p=0.4697)$ and $(p=0.1970)$ and SARA scale $(p=0.6182),(p=0.3818)$ and $(p=0.7273)$.

\section{Discussion}

The anamnesis showed the prevalence of gait imbalance (81.8\%) and of dysarthria (63.8\%) as the most reported complaints by the patients. As for tinnitus and hearing loss
(36.3\%), they were less reported by the patients, showing that they were not the main complaint among this population. These findings corroborate the study by Bürk et al, ${ }^{12}$ who reported gait imbalance and dysarthria as the most relevant complaints, observed in $100 \%$ of the cases.

In the present research, only $36.4 \%$ of the researched patients evidenced hearing impairments. Disregarding no significant difference, a higher proportion of altered cases was observed among older patients, as well as a longer time span of the disease. In relation to the SARA scale, there was a higher proportion of impairments among patients who scored higher, that is, with worse degrees of ataxia. This result matches the reported complaints of the patients, in which auditory issues did not have a significant prevalence.

Ikeda et $\mathrm{al}^{9}$ assessed several types of ataxia, with atrophy of multiple systems in the cerebellar prevalence, cortical cerebellar atrophy, and hereditary ataxias, including SCA 31, 
e90 Pure-Tone Hearing Thresholds and Brainstem Auditory Zeigelboim et al.

Table 5 Distributions of audiological, brainstem auditory evoked potential, and acoustic immittance test in 11 patients with sporadic ataxia

\begin{tabular}{|c|c|c|c|c|}
\hline \multirow[t]{2}{*}{ Audiology findings, $n$} & \multicolumn{2}{|c|}{ Disease duration (years) } & \multirow[t]{2}{*}{ TOTAL } & \multirow[t]{2}{*}{ p-value } \\
\hline & $4-8$ & $9-13$ & & \\
\hline Abnormal & 2 & 2 & 4 & \multirow[t]{2}{*}{0.6515} \\
\hline Normal & 4 & 3 & 7 & \\
\hline TOTAL & 6 & 5 & 11 & \\
\hline \multirow[t]{2}{*}{ Audiology findings, $n$} & \multicolumn{2}{|c|}{ Age (years old) } & \multirow[t]{2}{*}{ TOTAL } & \multirow[t]{2}{*}{ p-value } \\
\hline & $35-49$ & $50-58$ & & \\
\hline Abnormal & 1 & 3 & 4 & \multirow[t]{2}{*}{0.0879} \\
\hline Normal & 6 & 1 & 7 & \\
\hline TOTAL & 7 & 4 & 11 & \\
\hline \multirow[t]{2}{*}{ Audiology findings, $n$} & \multicolumn{2}{|c|}{ SARA (score) } & \multirow[t]{2}{*}{ TOTAL } & \multirow[t]{2}{*}{ p-value } \\
\hline & $\leq 9$ & $10-22.5$ & & \\
\hline Abnormal & 1 & 3 & 4 & 0.6182 \\
\hline Normal & 1 & 6 & 7 & \\
\hline TOTAL & 2 & 9 & 11 & \\
\hline \multirow[t]{2}{*}{ BAEP findings, $n$} & \multicolumn{2}{|c|}{ Disease duration (years) } & \multirow[t]{2}{*}{ TOTAL } & \multirow[t]{2}{*}{ p-value } \\
\hline & $4-8$ & $9-13$ & & \\
\hline Abnormal & 1 & 3 & 4 & \\
\hline Normal & 5 & 2 & 7 & 0.1970 \\
\hline TOTAL & 6 & 5 & 11 & \\
\hline \multirow[t]{2}{*}{ BAEP findings, $n$} & \multicolumn{2}{|c|}{ Age (years old) } & \multirow[t]{2}{*}{ TOTAL } & \multirow[t]{2}{*}{ p-value } \\
\hline & $35-49$ & $50-58$ & & \\
\hline Abnormal & 2 & 2 & 4 & \\
\hline Normal & 5 & 2 & 7 & 0.4697 \\
\hline TOTAL & 7 & 4 & 11 & \\
\hline \multirow[t]{2}{*}{ BAEP findings, $n$} & \multicolumn{2}{|c|}{ SARA (score) } & TOTAL & p-value \\
\hline & $\leq 9$ & $10-22.5$ & & \\
\hline Abnormal & - & 4 & 4 & \\
\hline Normal & 2 & 5 & 5 & 0.3818 \\
\hline TOTAL & 2 & 9 & 11 & \\
\hline Acoustic immittance findings, $n$ & Disease & & TOTAL & p-value \\
\hline & $4-8$ & $9-13$ & & \\
\hline Abnormal & 2 & 3 & 5 & \\
\hline Normal & 4 & 2 & 6 & 0.3918 \\
\hline TOTAL & 6 & 5 & 11 & \\
\hline Acoustic immittance findings, $n$ & Age (ye & & TOTAL & p-value \\
\hline & $35-49$ & $50-58$ & & \\
\hline Abnormal & 2 & 3 & 5 & \\
\hline Normal & 5 & 1 & 6 & 0.1970 \\
\hline TOTAL & 7 & 4 & 11 & \\
\hline Acoustic immittance findings, $n$ & SARA (s & & TOTAL & p-value \\
\hline & $\leq 9$ & $10-22.5$ & & \\
\hline Abnormal & 1 & 4 & 5 & \\
\hline Normal & 1 & 5 & 6 & 0.7273 \\
\hline TOTAL & 2 & 9 & 11 & \\
\hline
\end{tabular}

Abbreviation: BAEP, brainstem auditory evoked potential; SARA, scale for the assessment and rating of ataxia. 
and observed that the audiogram results did not show any significant difference or specificity in the impaired hearing levels among the ataxic groups, averaging $25.6 \mathrm{~dB}$ in the right ear and $29.2 \mathrm{~dB}$ in the left ear in the auditory assessment, corroborating the fact that the hearing issue was not their main complaint. As for Friedreich ataxia, an autosomal recessive inherited disease, studies showed that $90 \%$ of the patients had hearing loss, considering this result as an important finding in the differential diagnosis for cerebellar ataxias. ${ }^{10}$ For Zeigelboim et al, ${ }^{11}$ who assessed 30 patients with Friedreich ataxia, audiometric testing unveiled $43.3 \%$ of altered cases, with bilateral prevalence in $36.7 \%$ of them.

The evaluation of the neurophysiological integrity of the brainstem by the BAEP is due to the synchronicity of the neural element, which can be observed by the wave overlap, adequate morphology, wave latency, and interpeak intervals. The deterioration of the function of the nervous system, most of the time, occurs initially through the cortex, the subcortical regions, and, finally, the brainstem. ${ }^{23}$

Biacabe et al and Nachmanoff et $\mathrm{al}^{24,25}$ indicate that, in neurodegenerative diseases, the most evidenced auditory dysfunctions are observed in the BAEP and occur in the inferior colliculi, in the lateral lemniscus, and in the cochlear nucleus.

In the BAEP assessment, in the present study, abnormalities were observed in $36.4 \%$, prevalence of latency increase in waves I, III and V, and in the interpeak intervals I-III, I-V and III-V. Bürk et al ${ }^{12}$ assessed 104 patients with SA and observed prominent axonal neuropathy in the electrophysiological testing, with reduced amplitude in 50\% of the patients, and abnormal BAEP in $58.3 \%$ of the cases. In another study, Sinatra et $\mathrm{al}^{13}$ assessed 22 patients ( 15 with familial ataxia and 7 with SA), and evidenced altered BAEP in $72.7 \%$ of the cases. The authors did not find any correlations with the variables for age, gender, and time span of the disease, and reported that the result did not change after 15 and 24 months of follow-up. The authors suggested that the involvement of the auditory pathways must have a genetic cause. Zeigelboim et $\mathrm{al}^{11}$ assessed 30 patients with Friedreich ataxia and evidenced abnormalities in $56.6 \%$ of the cases, which were bilateral in $50 \%$.

Knezevic et al and Zeigelboim et al ${ }^{14,15}$ evidenced abnormality in 71 and $46.5 \%$ of the cases, respectively, in the BAEP assessment of autosomal recessive and dominant spinocerebellar ataxias. These authors found important abnormalities in the brainstem auditory pathways in these types of ataxias.

In the acoustic immittance measurement, we observed $45.4 \%$ of disorders. There is scarce literature for that finding. Zeigelboim et $\mathrm{al}^{11}$ reported disorders in $46.6 \%$ of the 30 assessed cases. However, in neurodegenerative diseases, the cochlear nucleus is affected, which may interfere in the mechanism of the acoustic reflex. ${ }^{26}$ In autosomal dominant spinocerebellar ataxia, studies reported $44.1 \%$ of abnormalities. ${ }^{15}$ In the present study, a greater abnormality was observed in the acoustic immittance measurement, specifically in the acoustic reflex investigation.

We emphasize the limited size of the sample as a consequence of the difficulty of attending patients to the place where the study was performed, due to the difficulty of locomotion of these subjects, as well as the need of an accompanying person to assist the patient to attend the service. Another limitation is related to the rare frequency of this type of ataxia in the population, as well as to the high mortality rate of those who have this condition. We suggest studies with a greater number of subjects, as well as longitudinal surveys for an auditory follow-up of those with sporadic ataxia.

\section{Conclusion}

The most evidenced abnormalities in the audiological testing were the prevalence of the descending audiometric configuration at frequencies between 2 and $4 \mathrm{kHz}$, bilaterally, and the absence of the acoustic reflex at the frequencies of 3 and $4 \mathrm{kHz}$, bilaterally.

In the electrophysiological assessment, abnormalities were observed with prevalence in the latency increase of waves I, III and V, as well as interpeak intervals I-III, I-V and III-V.

\section{Conflicts of Interests}

The authors have no conflicts of interests to declare.

\section{References}

1 Solodkin A, Gomez CM. Spinocerebellar ataxia type 6. Handb Clin Neurol 2012;103:461-473

2 Watanabe N, Lin J, Lin K. Hereditary progressive ataxia: 20 years from first symptoms and signs to diagnosis. ACM 2013;42:81-85

3 Manto M, Marmolino D. Cerebellar ataxias. Curr Opin Neurol 2009;22(04):419-429

4 Klockgether T. Sporadic ataxia with adult onset: classification and diagnostic criteria. Lancet Neurol 2010;9(01):94-104

5 Barsottini OGP, Albuquerque MV, Braga-Neto P, Pedroso JL. Adult onset sporadic ataxias: a diagnostic challenge. Arq Neuropsiquiatr 2014;72(03):232-240

6 Drumond MT, Prado M, Vasconcellos LF. Idiopathic late onset cerebellar ataxia (ILOCA): diagnostic challenge. Rev Bras Neurol 2015;51:18-20

7 Musiek FE, Baran JA. Central auditory assessment: thirty years of challenge and change. Ear Hear 1987;8(4, Suppl):22S-35S

8 Aquino AMCM. (org). Auditory processing: electrophysiology and psychoacoustics. São Paulo: Lovise; 2002

9 Ikeda Y, Nagai M, Kurata T, et al. Comparisons of acoustic function in SCA31 and other forms of ataxias. Neurol Res 2011;33(04):427-432

10 Mahmoud A. Central Vestibulopathies [Internet]. Available at: http://forl.org.br/Content/pdf/seminarios/seminario_19.pdf. Accessed July 14, 2017

11 Zeigelboim BS, Teive HAG, Rosa MRD, et al. The importance of central auditory evaluation in Friedreich's ataxia. Arq Neuropsiquiatr 2018;76(03):170-176

12 Bürk K, Bösch S, Müller CA, et al. Sporadic cerebellar ataxia associated with gluten sensitivity. Brain 2001;124(Pt 5):1013-1019

13 Sinatra MG, Baldini SM, Baiocco F, Carenini L. Auditory brainstem response patterns in familial and sporadic olivopontocerebellar atrophy. Eur Neurol 1988;28(05):288-290

14 Knezevic W, Stewart-Wynne EG. Brainstem auditory evoked responses in hereditary spinocerebellar ataxias. Clin Exp Neurol 1985;21:149-155

15 Zeigelboim BS, Teive HAG, Santos RS, et al. Audiological evaluation in spinocerebellar ataxia. CoDAS 2013;25(04):351-357 
16 Dueñas AM, Goold R, Giunti P. Molecular pathogenesis of spinocerebellar ataxias. Brain 2006;129(Pt 6):1357-1370

17 Pearson CE, Nichol Edamura K, Cleary JD. Repeat instability: mechanisms of dynamic mutations. Nat Rev Genet 2005;6(10):729-742

18 Schöls L, Bauer P, Schmidt T, Schulte T, Riess O. Autosomal dominant cerebellar ataxias: clinical features, genetics, and pathogenesis. Lancet Neurol 2004;3(05):291-304

19 Davis H, Silverman RS. Hearing and deafness. 3rd ed. New York: Holt Rinehart and Winston; 1970

20 Silman S, Silverman CA. Basic audiology testing. In: Silman S, Silverman CA. Auditory diagnosis, principles and applications. San Diego: Singular Publishing Group; 1997:38-58

21 Hall J. Handbook of auditory evoked responses. Boston: Allyn \& Bacon; 1992
22 Jerger J. Clinical experience with impedance audiometry. Arch Otolaryngol 1970;92(04):311-324

23 Musiek FE, Rintelman WF. Perspectivas atuais em avaliação auditiva. São Paulo: Manole; 2001

24 Biacabe B, Chevallier JM, Avan P, Bonfils P. Functional anatomy of auditory brainstem nuclei: application to the anatomical basis of brainstem auditory evoked potentials. Auris Nasus Larynx 2001; 28(01):85-94

25 Nachmanoff DB, Segal RA, Dawson DM, Brown RB, De Girolami U. Hereditary ataxia with sensory neuronopathy: Biemond's ataxia. Neurology 1997;48(01):273-275

26 Carvallo RMM. Imitância acústica. In: Zeigelboim BS, Jurkiewicz, AL. (org). Multidisciplinarity in otoneurology. São Paulo: Roca; 2012:122-130 